\title{
Are behavioral effects of early experience mediated by oxytocin?
}

\author{
Karen L. Bales ${ }^{1 *}$, Ericka Boone ${ }^{2}$, Pamela Epperson ${ }^{2}$, Gloria Hoffman ${ }^{3}$ and C. Sue Carter ${ }^{2}$ \\ Department of Psychology, University of California, Davis, CA, USA \\ 2 Brain-Body Center, Department of Psychiatry, University of Illinois, Chicago, IL, USA \\ ${ }^{3}$ Department of Biology, Morgan State University, Baltimore, MD, USA
}

\section{Edited by:}

Josephine Johns, University of North Carolina at Chapel Hill, USA

Reviewed by:

Frances A. Champagne, Columbia University, USA

Larry J. Young, Emory University

School of Medicine, USA

*Correspondence:

Karen L. Bales, Department of Psychology, University of California, 135 Young Hall, Davis, CA 95616, USA. e-mail:klbales@ucdavis.edu
Early experiences can alter adaptive emotional responses necessary for social behavior as well as physiological reactivity in the face of challenge. In the highly social prairie vole (Microtus ochrogaster), manipulations in early life or hormonal treatments specifically targeted at the neuropeptides oxytocin (OT) and arginine vasopressin (AVP), have long-lasting, often sexually dimorphic, consequences for social behavior. Here we examine the hypothesis that behavioral changes associated with differential early experience, in this case handling the family during the first week of life, may be mediated by changes in OT or AVP or their brain receptors. Four early treatment groups were used, differing only in the amount of manipulation received during the first week of life. MAN1 animals were handled once on post-natal day 1; MAN1 treatment produces a pattern of behavior usually considered typical of this species, against which other groups were compared. MAN1-7 animals were handled once a day for post-natal days 1-7, MAN 7 animals were handled once on post-natal day 7, and MANO animals received no handling during the first week of life. When tested following weaning, males in groups that had received manipulation during the first few days of life (MAN1 and MAN1-7) displayed higher alloparenting than other groups. Neuroendocrine measures, including OT receptor binding and OT and AVP immunoreactivity, varied by early treatment. In brain areas including the nucleus accumbens, bed nucleus of stria terminalis and lateral septum, MANO females showed increased OT receptor binding. MAN1 animals also displayed higher numbers of immunoreactive OT cell bodies in the supraoptic nucleus. Taken together these findings support the broader hypothesis that experiences in the first few days of life, mediated in part by sexually dimorphic changes in neuropeptides, especially in the receptor for OT, may have adaptive consequences for sociality and emotion regulation.

Keywords: oxytocin, vasopressin, monogamy, parental care, anxiety

\section{INTRODUCTION}

The role of early experience in the development of adult behavior and psychopathology has been of considerable interest to neurobiologists for decades (Harlow, 1961, 1964; Harlow and Suomi, 1971; Hofer, 1978, 2006; Plotsky, 1997, 2002; Levine, 2002a). Early neglect or traumatic experiences may increase vulnerability in later life, contributing to the symptoms associated with depression, anxiety disorders, substance abuse, and post-traumatic stress disorder (Heim et al., 1997; Henry and Wang, 1998; Plotsky et al., 1998; Sanchez et al., 2001; Gilmer and McKinney, 2003; Advani et al., 2007; Francis and Kuhar, 2008). In contrast, early experiences can have positive consequences for later sociality (Carter et al., 2009) and emotion regulation (Francis et al., 2002a), disease resistance (Nithianantharajah and Hannan, 2006), and memory (Berardi et al., 2007; Herring et al., 2008), among other variables.

A rich literature chronicles the behavioral and physiological effects of early handling in rodents (Levine, 1957; Levine and Lewis, 1959b; Denenberg et al., 1962; Denenberg and Whimbey, 1963), particularly focused on stress reactivity of the offspring (Levine, 2002b). Short separations from the mother tend to produce offspring that display improved capacities to manage a social or physical challenge (Levine, 2005; Aguilar, 2010; Zanettini et al., 2010), though this was not true in every study (Todeschin et al., 2009); while either drastically reduced handling or long separations tend to produce offspring that are hyper-responsive to stressors (Levine, 2002a). It is often hypothesized that this effect is maternally mediated, possibly due to increases in maternal attention to infants upon reunion, although alternative hypotheses have also been suggested (Denenberg et al., 1962; Denenberg and Whimbey, 1963; Smotherman and Bell, 1980; Boccia and Pedersen, 2001; Tang, 2001; Tang et al., 2006; Macri et al., 2008). Sex differences in the response to early handling are also a consistent finding, although these differences are not always in the same direction (Eklund and Arborelius, 2006; Slotten et al., 2006; Bales et al., 2007a; Renard et al., 2007; Aisa et al., 2008; Desbonnet et al., 2008).

Other studies have also linked changes in mothering behavior in rats, whether spontaneously occurring or induced by an intervention, to changes in the oxytocin (OT) and arginine vasopressin (AVP) systems (Francis et al., 2000, 2002b; Champagne et al., 2001; Pedersen and Boccia, 2002). In adults, OT and AVP have been implicated in social behaviors, including pair-bonding (Winslow et al., 1993; Williams et al., 1994; Cho et al., 1999; Lim 
et al., 2004), parental behavior (Pedersen et al., 1982; Wang et al., 1994; Bales et al., 2004b), and also measures of anxiety (Neumann, 2002). Increases in oxytocin receptors (OTR) in the central amygdala and bed nucleus of the stria terminalis (BNST) in female offspring, and AVP V1a receptor (V1aR) binding in the central amygdala in male offspring (Francis et al., 2002b), have also been associated with increased maternal licking.

Prairie voles are small rodents, native to the midwestern United States. Members of this species show high levels of social behavior and display a monogamous social system, characterized by biparental care and a strong preference for a pair-mate, measured both in the field and in the laboratory (Getz et al., 1981; Carter et al., 1995). These species-typical traits can be influenced by apparently small differences in experience during the first few days of life (Bales et al., 2007a). Animals from families that were manipulated, by picking up the family for a few minutes during the first day of post-natal life (MAN1) were compared to prairie voles in which external manipulations of the family were minimized by not disturbing the family during the first few days of life (termed MAN0). Behavioral differences in later life were striking and in some cases sexually dimorphic. When tested with pups following weaning, MAN0 males showed low levels of alloparenting (i.e., spontaneous display of parenting-like behavior by juveniles). Tested in adulthood, selective social behaviors indicative of pair-bonding were disrupted; in this case the effect was especially obvious in females. Female prairie voles that received reduced early handling (MAN0) did not exhibit selective preferences for a familiar male, even when given six times the amount of exposure to a male that is typically sufficient to induce a preference. In addition, in both sexes tested in adulthood, MAN0 animals showed increased anxiety-like behaviors when tested in an elevated plus-maze (EPM). We hypothesize that these differences are due primarily to an early environment that is for MAN0 offspring less enriched or even impoverished. We further hypothesize even a small amount of handling (which typically occurs during cage change in most animal facilities) is sufficient to produce changes in the parental-infant interactions, which in turn leads to species-typical levels of behaviors in the offspring in later life. The effects of this manipulation were discovered serendipitously. However, the MAN1 versus MAN0 model for the effects of early experience is advantageous in some ways, in that this comparison is based on a subtle manipulation of early experience and one in which other variables (e.g., time away from the parents or temperature) are held relatively constant. Because young voles have milk-teeth and are attached to the mother during the handling manipulation, direct contact with the pups is avoided and we hypothesize that observed group differences are due to changes in the behavior of the parents (Tyler et al., 2005).

Evidence from other rodent species suggests that the effects of early experience can be time dependent and especially potent during the first week of life. However, responses to early handling may differ by species or even within the same strains of a given species (Holmes et al., 2005; Enthoven et al., 2008). Although early work in this field, primarily done in rats, tended to emphasize direct effects of handling on the offspring, more recent evidence suggests that individual differences in maternal behavior or maternal responses to disruption may significantly influence subsequent behavioral outcomes.
Consistent with our own findings in voles (Carter et al., 2009), and earlier work in rats (Champagne et al., 2001; Francis et al., 2002b; Todeschin et al., 2009), we hypothesized here that the effects of parental stimulation or its absence in post-natal life might be mediated by alterations in the OT or AVP systems. One purpose of the present study was to use the vole manipulation model to examine the effects of differential early experience on OT and AVP systems, measured in later life; here we have measured indices of central peptide synthesis, as well as receptor binding for the OTR and the AVP V1aR. We also examined the hypothesis that the age at which manipulations occurred and the frequency of handling might influence behavior or endocrine outcomes. Based on the outcome of earlier studies we predicted that groups receiving reduced stimulation in the first days of life would be less likely to be alloparental and more likely to show indices of anxiety, such as reduced exploration of or autogrooming in an EPM, and to show associated changes in the release of the adrenal steroid, corticosterone (CORT). We further predicted that changes in behavior would be associated with the parallel changes in the endogenous OT system, indexed by measures of OT synthesis or receptor binding. Also measured were possible experience-induced changes in cells synthesizing AVP and receptor binding in the AVP V1aR. Here we chose to examine outcome measures in juveniles due to our previous finding of low alloparenting in juvenile males (Bales et al., 2007a); future work will examine the same measures in adults.

\section{MATERIALS AND METHODS EARLY MANIPULATIONS}

Subjects were laboratory-bred male and female prairie voles (Microtus ochrogaster), descendants of a wild stock originally caught near Champaign, IL, USA. Stock was systematically outbred. Animals were maintained on a 14-h light: 10-h dark cycle and given food (highfiber Purina rabbit chow) and water ad libitum. Breeding pairs were maintained in large polycarbonate cages $(44 \mathrm{~cm} \times 22 \mathrm{~cm} \times 16 \mathrm{~cm})$ and provided with cotton for nesting material. Litters varied from 4 to 6 offspring and were not culled to avoid any additional handling. At 20 days of age offspring were removed and housed in same-sexed sibling pairs in smaller $(27 \mathrm{~cm} \times 16 \mathrm{~cm} \times 13 \mathrm{~cm})$ cages. The goal was 10 animals of each sex for each handling group; actual numbers of animals varied by outcome variable.

Sixteen multiparous pairs were used as breeders. The first treatment was assigned randomly for each pair. For the next litter, each pair received a different treatment (no pair received the same treatment more than once). There were four early handling treatments, here referred to as MAN0, MAN1, MAN1-7, and MAN7. MAN1 litter handling involved lifting the parents by the scruff of the neck with a hand covered in a thick leather glove. Pups were attached to the mother by milk-teeth and therefore were not touched (if pups were not attached, researchers waited to perform the manipulation). MAN1-7 received an identical manipulation once a day for 7 days postpartum, while MAN7 received this manipulation once on day 7. MAN0 litters were lifted briefly in a clear plastic cup. Sitting animals were scooped into the cup. If the animal was moving, the cup was maneuvered in front of the animal as it walked into it. In this manipulation, infants would be supported by the cup while being moved, rather than dangling from the mother's nipples. Cages were changed in the day preceding birth (almost always the 
day after the previous litter was weaned). Thereafter, cages were changed on day 7 and cage-changing was kept constant across groups. During subsequent cage changes, all animals were moved to the new cage in a cup. MAN0 litters were therefore manipulated in the cup three times (one for the early manipulation, two other times for cage-cleaning). The other groups received their described early manipulation (cup or hand) and all subsequent cage changes were performed by cup.

On day 20 postpartum, the infants were weaned and housed in same-sex pairs throughout testing. In order to utilize all of the offspring from each litter two experimental groups were formed, as described here.

\section{Experimental group 1}

On day 21-25, this group was tested in an alloparental care test (see methods below). The following day, they received an EPM test. The day following that, they were anesthetized with ketamine and xylazine, received an eyebleed, and were euthanized by cervical dislocation under deep anesthesia. Brains were flash-frozen for use in receptor autoradiography.

\section{Experimental group 2}

On day 21-25, these animals were removed from their cage, immediately anesthetized with ketamine and xylazine, received an eyebleed (data not presented here), and were euthanized by cervical dislocation under deep anesthesia. Brains were passively perfused for use in immunohistochemistry (methods detailed below), and sliced at $40 \mu \mathrm{m}$ thickness on a sliding microtome.

All studies were approved by the Animal Care and Use Committee of the University of Illinois, Chicago, IL, USA and complied with National Institutes of Health ethical guidelines as set forth in the Guide for Lab Animal Care.

\section{BEHAVIORAL TESTING}

All behavioral testing was performed between 08:00 and 12:00 h.

\section{Alloparental care testing}

Animals were always weaned before the birth of the next litter in their home cage, thus ensuring that previous exposure to neonates had not occurred. Test animals were introduced into an apparatus which consisted of two cages connected by a $5 \mathrm{~cm}$ clear tube, and given 45 min to acclimate. Two pups (1-3 days old) were then introduced into one cage. The test animal was exposed to the pups for $10 \mathrm{~min}$ (methods based on (Roberts et al., 1998). If the test animal showed any pup-directed aggression, the test was stopped immediately and the pups removed and treated as necessary. Aggression displayed by 21-day olds rarely results in significant injury to the infant. Behaviors were scored from videotape by an observer blind to experimental treatment on behavioral software (Behavior Tracker, www.behaviortracker.com) for sniffing, huddling, non-huddling contact (any contact with pups not covered by another category), retrievals, licking/grooming, and aggression.

\section{ANALYSIS STRATEGY}

Data analysis was carried out by ANOVA. Residuals were checked for normality. All significance levels were set at $p<0.05$ and all tests were two-tailed. We also conducted planned comparisons between MAN1 and MAN0 animals, to determine replicability of earlier findings with these groups, and to specifically examine possible neuroendocrine correlates of behavioral changes between these groups. In some cases, we also combined groups that received manipulations during the first week (MAN1 and MAN1-7) and groups that did not receive manipulation during the first week (MAN0 and MAN7).

\section{Elevated Plus-maze testing}

This test examines responses to nonsocial stimuli associated with a novel environment, and also has been used as a form of mild stressor (Insel et al., 1995; Ramos and Mormede, 1998). Time spent in the closed arm of the EPM is considered a measure of anxiety or fear response, due to the fact that presumably most rodents find open spaces aversive. Behavior in the EPM is responsive to both anxiolytic and anxiogenic drugs, and fear responses in the EPM have been found to be fairly resistant to environmental conditions (Ramos and Mormede, 1998). Prairie voles may find open areas less aversive than do other rodents such as meadow voles, a closely related polygynous species (Stowe et al., 2005), but EPM behavior in prairie voles has been shown to be responsive to manipulations such as injection of vasopressin (Dharmadhikari et al., 1997) and early handling (Bales et al., 2007a).

The EPM consisted of two open and two closed, opaque arms, each 67-cm long and 5.5-cm wide (Insel et al., 1995), elevated $1 \mathrm{~m}$ above the floor. Each vole was placed in the neutral area in the center of the EPM and its behavior scored for five minutes using Behavior Tracker. Plus-maze activity was indexed as time spent in the open $\mathrm{arm} /($ time spent in the open arm + time spent in the closed arm). Data were analyzed by mixed model ANOVAs (Littell et al., 1996) in SAS 9.2 (SAS Institute, Cary, NC, USA). All significance levels were set at $p<0.05$ and all tests were two-tailed.

\section{HORMONE ASSAYS}

Plasma OT was assayed using a commercial enzyme immunoassay (Assay Designs, Ann Arbor, MI, USA, now Enzo Life Sciences), validated for use in the prairie vole (Kramer et al., 2004). Nonextracted samples were diluted at 1:8 for OT (40 $\mu$ l of plasma) and 1:12 for AVP (25 $\mu$ l of plasma) and assayed according to kit instructions. Intra-assay c.v. for OT was $1.5 \%$ and inter-assay c.v. was $13.5 \%$. For AVP intra-assay c.v. was $1.2 \%$ and inter-assay c.v. was $2.9 \%$.

Corticosterone was assayed using a radioimmunoassay (MP Biomedicals, Irvine, CA, USA) previously validated for the prairie vole (Taymans et al., 1997). Non-extracted samples were assayed at 1:2000 dilution in order to insure that all samples fell on the standard curve. Intra-assay c.v.s averaged $3.7 \%$ and inter-assay c.v. was $4.3 \%$.

\section{RECEPTOR AUTORADIOGRAPHY}

Following sacrifice, brains were quickly removed, flash-frozen on dry ice and stored at $-80^{\circ} \mathrm{C}$. Brains were sectioned at $20-\mu \mathrm{m}$ thickness, mounted onto Super-frost slides, and stored at $-80^{\circ} \mathrm{C}$ until the time of assay. Sections were allowed to thaw to room temperature and then immersed in $0.1 \%$ paraformaldehyde for 2 min to optimize tissue integrity. Sections then were rinsed three times in $50 \mathrm{mM}$ Tris- $\mathrm{HCl}(\mathrm{pH} \mathrm{7.4)}$ at room temperature 
for $5 \mathrm{~min}$ and incubated for $60 \mathrm{~min}$ at room temperature in a solution of $50 \mathrm{mM}$ Tris- $\mathrm{HCl}$ (pH 7.4) with $10 \mathrm{mM} \mathrm{MgCl}, 0.1 \%$ bovine serum albumin, and $50 \mathrm{pM}$ of radiotracer. For OTR binding, $\left[{ }^{125} \mathrm{I}\right]$-ornithine vasotocin analog $\left[\left({ }^{125} \mathrm{I}\right) \mathrm{OVTA}\right]$ was employed [vasotocin, $\mathrm{d}\left(\mathrm{CH}_{2}\right)_{5}\left[\mathrm{Tyr}(\mathrm{Me})^{2}, \mathrm{Thr}^{4}, \mathrm{Orn}^{8},\left({ }^{125} \mathrm{I}\right) \mathrm{Tyr}^{9}-\mathrm{NH}_{2}\right] ; 2200$ $\mathrm{Ci} / \mathrm{mmol}$; (NEN Nuclear, Boston, MA, USA). For V1aR binding, ${ }^{125} \mathrm{I}$-lin-vasopressin $\quad{ }^{125} \mathrm{I}$-phenylacetyl-D-Tyr(ME)-Phe-GlnAsn-Arg-Pro-Arg-Tyr-NH 2 ; (NEN Nuclear) was used. Nonspecific binding was determined by incubating adjacent sections with the radioactive specific ligand as well as with $50 \mu \mathrm{M}$ of unlabeled $\mathrm{Thr}^{4}$, Gly ${ }^{7} \mathrm{OT}$, a selective OT ligand (Peninsula Laboratories, Belmont, CA, USA) or $50 \mu \mathrm{M}$ of unlabeled [1-(-mercapto-,-cyclopentamethylene propionic acid),2-( $O$-methyl)-tyrosine]-arg8vasopressin, selective for the V1aR. Following incubation, sections were washed four times at $5 \mathrm{~min}$ each in $50 \mathrm{~mm}$ Tris- $\mathrm{HCl}(\mathrm{pH}$ 7.4) with $10 \mathrm{mM} \mathrm{MgCl}_{2}$ at $4^{\circ} \mathrm{C}$, followed by a final rinse in this same buffer for $30 \mathrm{~min}$ while stirred with a magnetic bar. Slides then were quickly dipped in cold $\mathrm{dH}_{2} \mathrm{O}$ and rapidly dried with a stream of cold air. Sections were apposed to Kodak BioMaxMR film (Kodak, Rochester, NY, USA). Autoradiographic ${ }^{125}$ I-receptor binding was quantified from film using the NIH Image program to measure uncalibrated optical density. Background was quantified for each slide from a cortical area lacking receptors. The number of slides scored for each area varied, but averaged approximately nine sections per area. Both sides of each area were quantified separately, compared for any differences according to hemisphere (which were not found), then a mean obtained for each slice. A mean for the area for each animal was then calculated, which was the value used in analyses.

\section{IMMUNOHISTOCHEMISTRY}

Free-floating tissue sections were rinsed in 0.05 M KPBS. To block endogenous peroxidase activity, sections were incubated for $15 \mathrm{~min}$ in $0.014 \%$ phenylhydrazine and then rinsed in KPBS. Next, sections were incubated in rabbit OT antisera (generously provided by Dr. Mariana Morris) at 1:150,000 or rabbit antiAVP (MP Biomedicals, Irvine, CA, USA) at 1:100,000 dilution in $0.05 \mathrm{M} \mathrm{KPBS}-0.4 \%$ Triton $\mathrm{X}-100$ ( $1 \mathrm{~h}$ at room temperature and then $48 \mathrm{~h}$ at $4^{\circ} \mathrm{C}$ ).

Sections were rinsed in KPBS before being incubated for $1 \mathrm{~h}$ at room temperature in biotinylated goat, anti-rabbit IgG (1:600 dilution in KPBS-0.4\% Triton X-100; H + L, BA-1000; Vector Laboratories, Burlingame, CA, USA). Sections were rinsed in KPBS and then incubated in an avidin-biotin peroxidase complex (4.5 A and $4.5 \mu \mathrm{B}$ per $1 \mathrm{ml} \mathrm{KPBS}-0.4 \%$ Triton X-100; Vectastain ABC kit-elite pk-6100 standard; Vector Laboratories) for $1 \mathrm{~h}$ at room temperature. Sections were rinsed in KPBS and then rinsed in $0.175 \mathrm{M}$ sodium acetate. Finally, OT-immunoreactivity (OT-IR) and AVP-IR were visualized by incubation in a nickel sulfate-diaminobenzidine chromogen solution (250 mg Nickel II Sulfate, $2 \mathrm{mg}$ $\mathrm{DAB}, 8.3 \mu \mathrm{l} 3 \% \mathrm{H}_{2} \mathrm{O}_{2}$ per $10 \mathrm{ml} 0.175 \mathrm{M}$ sodium acetate) for $15 \mathrm{~min}$, then rinsed in sodium acetate followed by KPBS rinses. Following labeling for OT or AVP, sections were mounted onto subbed glass slides and air-dried overnight. Sections then were dehydrated in ascending ethanol solutions, cleared in Histoclear (National Diagnostics, Atlanta, GA, USA), and the slides were coverslipped with Histomount (National Diagnostics).
Images were captured using a Nikon Eclipse E 800 microscope, Sensi-cam camera, and IP Lab Software ${ }^{\circledR}$. Pictures for analysis were taken at $100 \times$ magnification. Analysis was performed using Image J software (National Institutes of Health, Bethesda, MD, USA). Density of staining within each nucleus was quantified using the threshold function to separate stained cells and fibers from the background. Within the PVN and SON, a standardized sampling area was used to determine the number of pixels labeled using the thresholding function. This was done to ensure that differences were not a result of variability in defining the borders of a nucleus. Density was calculated as the percentage of threshold labeled pixels versus non-labeled pixels within the entire sampling area. Similar methods have been used to determine differences in OT and AVP cell and fiber staining in other studies (Wang et al., 1996; BesterMeredith and Marler, 2003; Ruscio et al., 2007). Density measurements from each nucleus were taken from sections matched in rostral-caudal orientation to minimize variability. In all cases, density measures were taken by two observers blind to the condition of the subject and the average was calculated. Due to the high concentration of cells and fibers within certain nuclei, we felt that cell counts would not be accurate as it was often not possible to discern exact cell numbers (due to overlapping cells) and cells from fibers within the central portions of densely stained nuclei.

Arginine vasopressin and OT densities were measured in the PVN and SON. Measurements within the PVN were taken in a caudal section of the nucleus where the stained cells and fibers take a characteristic shape and branching pattern, as demonstrated in previous studies (Wang et al., 1996). This section is further characterized by the medial-lateral position of the fornix (relative to the third ventricle) and medial and dorsal location of the optic tract (relative to more central and ventral position in more rostral sections). It is approximate to Figure 49 in Paxinos and Watson (2005). Two density measures within each section were taken; one in the center (sampling area: $125 \mu \mathrm{m} \times 125 \mu \mathrm{m}$ ) measuring both cells and fibers, and another in the periphery (sampling area: $375 \mu \mathrm{m} \times 250 \mu \mathrm{m}$ ) measuring projecting fibers from the PVN. AVP and OT density measurements in the SON were taken at the same rostral-caudal level as the PVN. Because of the SON's curved shape and location, we used two areas to ensure that the optic tract was not included in the thresholding function. Both measures (sampling areas: horizontal, $282 \mu \mathrm{m} \times 375 \mu \mathrm{m}$ and vertical $225 \mu \mathrm{m} \times 440 \mu \mathrm{m})$ were within the SON (cells and fibers) and the density was the sum of stained fibers and cells with both areas.

\section{RESULTS \\ ALLOPARENTAL BEHAVIOR}

When groups that were manipulated before day 7 (MAN1 and MAN1-7) were combined and compared to groups that were not manipulated before day 7 (MAN0 and MAN7), they differed significantly in alloparental behavior. Males that were manipulated before day 7 displayed a significantly longer duration of non-huddling contact ( $n=42, F_{1}=4.95, p=0.035$; Figure 1$)$ and total time spent in alloparental behavior (including sniffing, licking/grooming, non-huddling contact, and huddling; $F_{1}=4.24, p=0.046$ ). When only MAN0 and MAN1 males were compared directly, there was a trend for a difference in non-huddling contact $\left(n=20, F_{1}=3.79\right.$, $p=0.067$ ) and other behaviors were non-significant (Table 1). In 
a one-tailed test (justified by a priori expectation of direction), the difference between MAN0 and MAN1 in non-huddling contact is significant $(p=0.033)$.

No female alloparental behaviors varied significantly by early treatment (Table 1). When MAN0 and MAN1 females were compared directly, there were also no significant differences in alloparental behaviors.
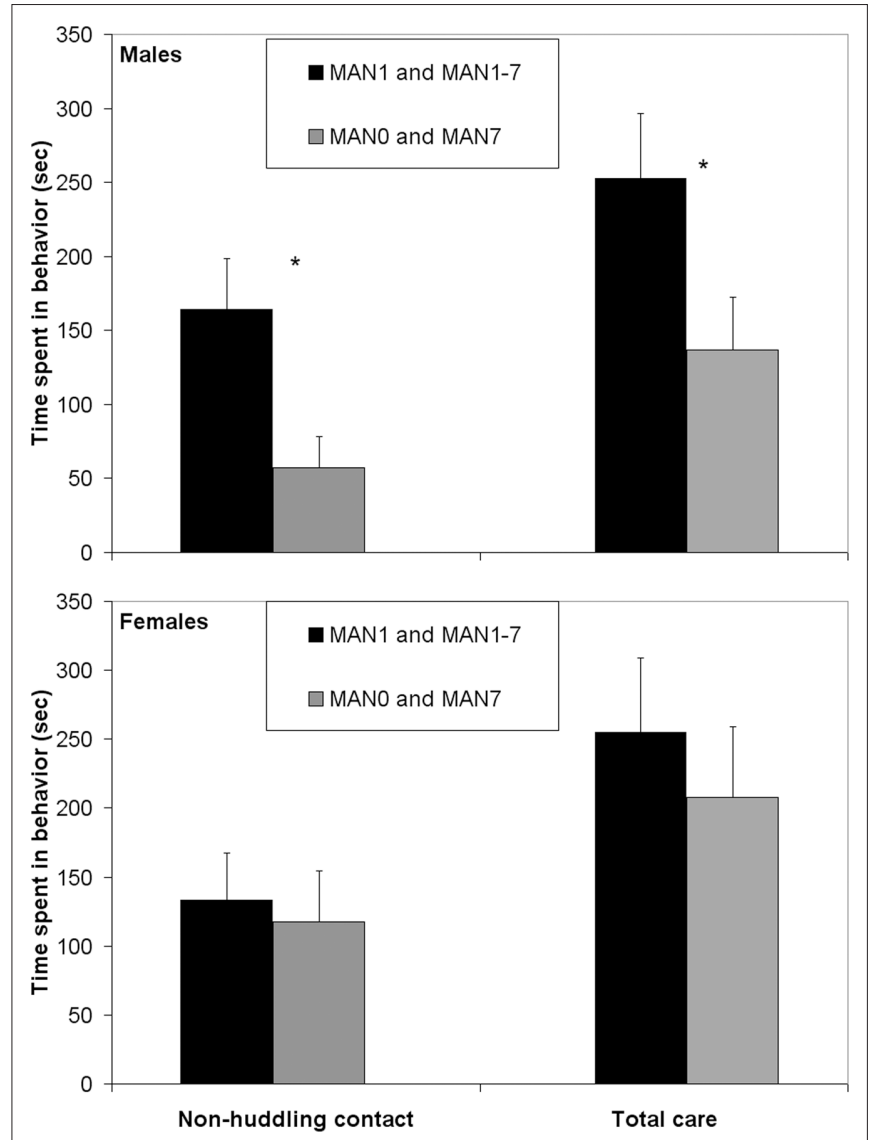

FIGURE 1 | Males that were manipulated before day 7 displayed a significantly longer duration of non-huddling contact $\left(F_{1}=4.95, p=0.035\right.$; Table 1$)$ and total time spent in alloparental behavior $\left(F_{1}=4.24, p=0.046\right)$.

\section{ELEVATED PLUS-MAZE}

Autogrooming in the EPM differed by treatment for females ( $n=39, F_{3}=4.38, p=0.012$; Figure 2$)$ but not for males $(n=38$, $\left.F_{3}=0.98, p=0.414\right)$. While time spent in the open arm, and the ratio of time spent in the open arm over time spent in both arms did not differ for either sex, in females there was a trend (Kruskal-Wallis test, $\chi^{2}=7.14, p=0.067$; Figure 2) for treatment to influence time spent in the closed arms, with MAN7 and MAN1-7 spending the most time there.

When only MAN1 and MAN0 groups were compared, no significant differences for males were seen; however MAN1 females autogroomed significantly more than MAN0 females $(n=19$, $F_{1}=4.87, p=0.041$; note though, that this was opposite the predicted direction) and tended to spend more time in the closed arms $\left(F_{1}=3.38, p=0.084\right)$.

\section{OXYTOCIN AND ARGININE VASOPRESSIN (V1A) RECEPTOR BINDING}

Oxytocin receptor binding differed in several areas in females, with MAN0 females having significantly higher OTR binding than other groups (Figures 3 and 4). Treatment differences were significant in the BNST $\left(n=26, F_{3}=3.37, p=0.032\right)$ and the nucleus accumbens (NAcc; $F_{3}=2.96, p=0.048$ ). OTR binding in females was also marginally significant in the same direction in the cingulate cortex $\left(F_{3}=2.89, p=0.051\right.$; optical densities, MAN1 $=0.107 \pm 0.03$, MAN1-7 $=0.115 \pm 0.02$, MAN7 $=0.126 \pm 0.3$, MAN0 $=0.248 \pm 0.06)$ and the lateral septum (LS; $F_{3}=2.97, p=0.054$; optical densities, MAN1 $=0.114 \pm 0.03$, MAN1 $-7=0.15 \pm 0.02$, MAN7 $=0.181 \pm 0.7$, MAN0 $=0.289 \pm 0.09$ ). OTR binding in males differed significantly in the BNST $(n=34$, $F_{3}=3.85, p=0.018$; Figure 5), and tended to differ in the NAcc $\left(F_{3}=2.65, p=0.065\right)$. These differences were in the same direction as females (MAN0 and MAN7 higher than MAN1), with even higher levels in some groups.

When comparing across the four groups there were no significant treatment group differences in either males or females in V1aR binding (Tables 2 and 3). Pre-planned comparisons of MAN1 and MAN0 groups did not reveal any significant differences in V1aR, when compared in separate brain areas. Though non-significant, it may be important to note that the levels of V1a binding in each of the brain areas studied was higher in MAN0 males versus MAN1 males. This pattern was not seen in females.

Table 1 |Alloparental behaviors in a pup test, including time spent in infant care and contact (non-huddling) were more common in prairie voles that were handled at least once in the first few days of life (MAN1 and MAN1-7) versus those that received no handling until at least PND 7 (MAN0 and MAN7).

\begin{tabular}{|c|c|c|c|c|c|c|c|c|}
\hline & $\begin{array}{l}\text { MALE: } \\
\text { Manipulation in } \\
\text { the first week } \\
\text { (MAN1 and } \\
\text { MAN1-7; } n=21 \text { ) }\end{array}$ & $\begin{array}{l}\text { MALE: No early } \\
\text { manipulation } \\
\text { (MAN0 and } \\
\text { MAN 7; } n=21 \text { ) }\end{array}$ & Statistic & $p$-value & $\begin{array}{l}\text { FEMALE: } \\
\text { Manipulation in } \\
\text { the first week } \\
\text { (MAN1 and } \\
\text { MAN1-7; } n=20 \text { ) }\end{array}$ & $\begin{array}{l}\text { FEMALE: No early } \\
\text { manipulation } \\
\text { (MANO and MAN 7; } \\
n=20 \text { ) }\end{array}$ & Statistic & $p$-value \\
\hline Sniff & $31.52 \pm 4.13$ & $37.86 \pm 6.86$ & $F=0.21$ & 0.653 & $17.85 \pm 3.2$ & $24.36 \pm 4.79$ & $F=0.38$ & 0.768 \\
\hline Lick & $56.0 \pm 18.67$ & $36.86 \pm 15.58$ & $\chi^{2}=2.01$ & 0.156 & $70.05 \pm 37.32$ & $49.47 \pm 18.68$ & $\chi^{2}=2.33$ & 0.507 \\
\hline Huddling & $1.24 \pm 0.86$ & $5.71 \pm 4.15$ & $\chi^{2}=1.11$ & 0.737 & $33.9 \pm 23.22$ & $16.32 \pm 9.23$ & $\chi^{2}=5.04$ & 0.169 \\
\hline
\end{tabular}



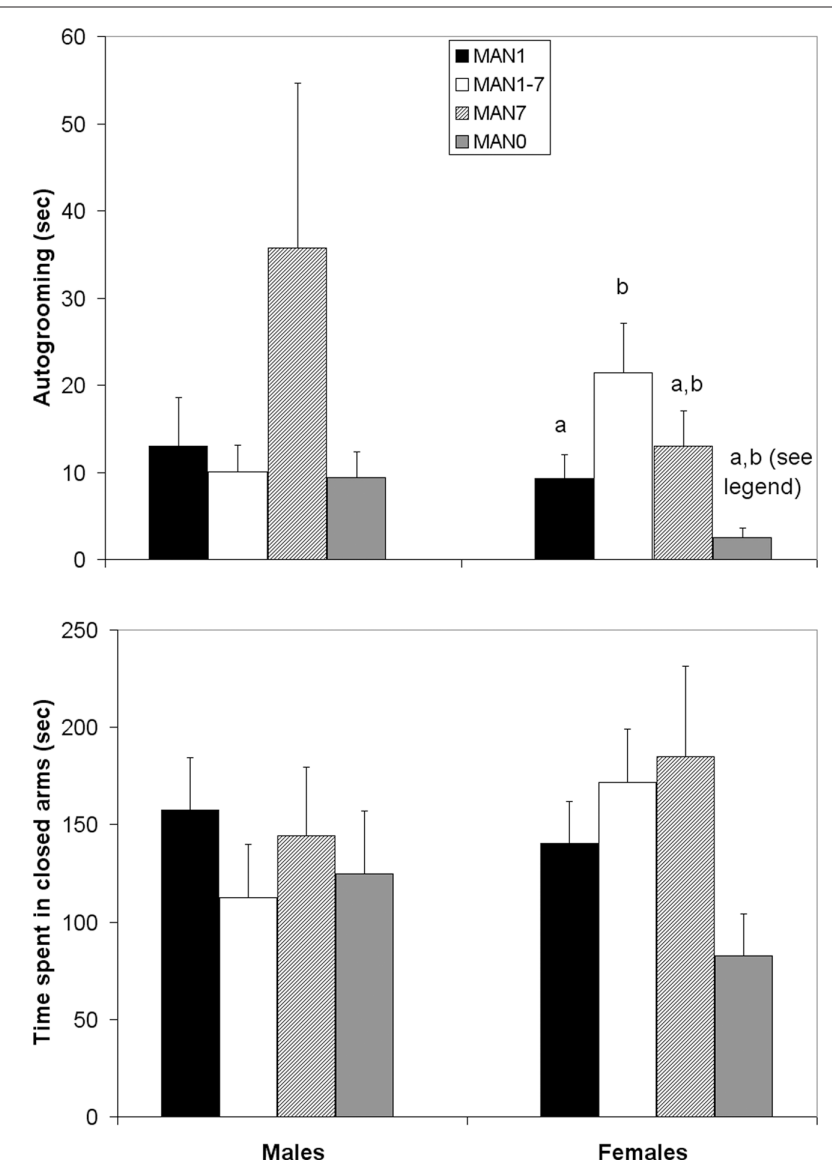

FIGURE 2 |Time spent autogrooming in the elevated plus-maze differed among treatment groups in females $\left(\boldsymbol{F}_{3}=\mathbf{4 . 3 8}, \boldsymbol{p}=\mathbf{0 . 0 1 2}\right)$. There was a trend for time spent in the closed arms to differ (Kruskal-Wallis test, $\chi^{2}=7.14$, $p=0.067)$. Groups which differ significantly from each other in the overall ANOVA are indicated by different letters. When MAN1 and MANO females were compared directly in pre-planned comparisons, MAN1 females autogroomed significantly more than MANO females $\left(F_{1}=4.87, p=0.041\right)$ and MAN1 females tended to spend more time in the closed arms than MANO females $\left(F_{1}=3.38, p=0.084\right)$.

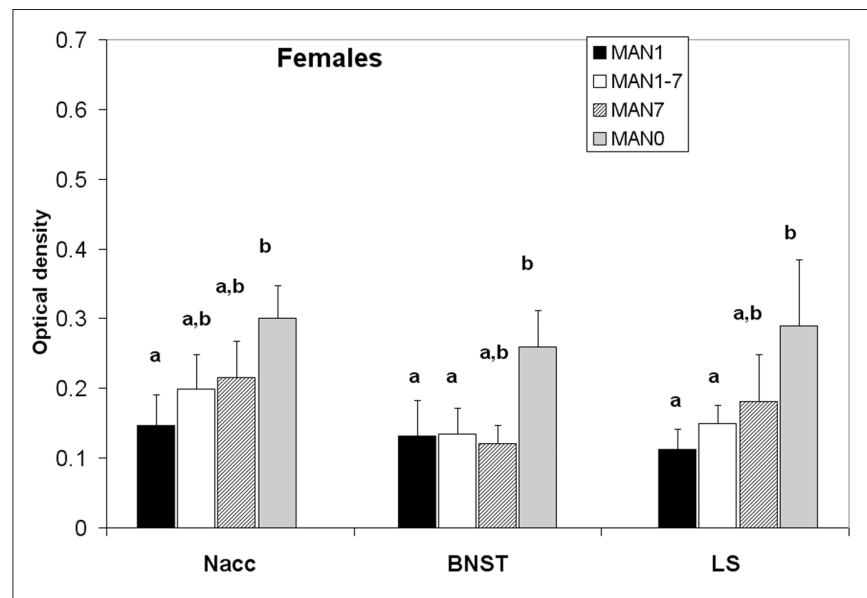

FIGURE 3 | Oxytocin receptor binding (optical density), females. Bars with different letters indicate groups that are significantly different in post hoc testing.
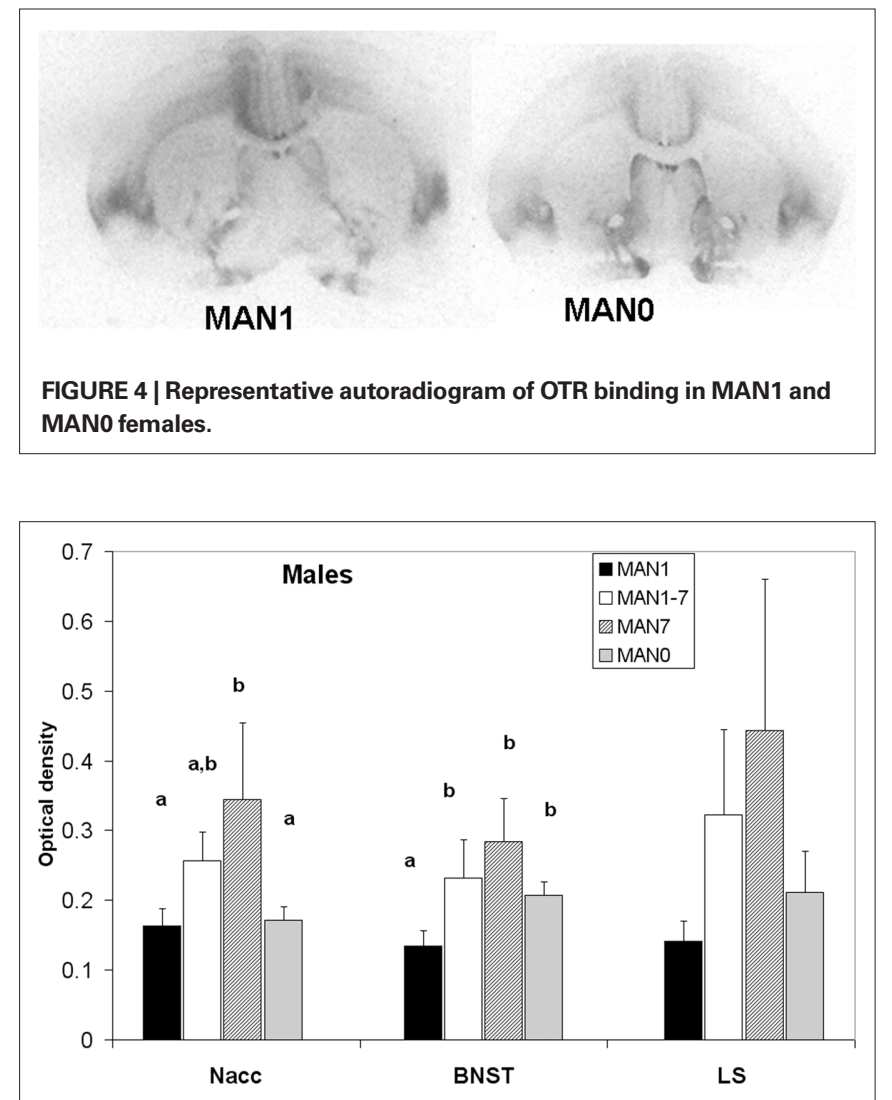

FIGURE 5 | Oxytocin receptor binding (optical density), males. Bars with different letters indicate groups that are significantly different in post hoc testing.

\section{CENTRAL OT AND AVP PRODUCTION (IMMUNOHISTOCHEMISTRY)}

The density of OT cell bodies in the SON differed significantly by treatment for males $\left(n=33, F_{3}=4.12, p=0.018\right.$; Figures 6 and 7$)$, but not for females $\left(n=27, F_{3}=1.9, p=0.157\right)$, although results were in the same direction in both sexes with MAN1 higher than other groups.

The density of OT fibers in the SON did not differ by treatment, and neither the density of OT cell bodies, nor the density of OT fibers, differed significantly in the PVN. No measures of AVP production (SON cell bodies, SON fibers, PVN cell bodies, PVN fibers) differed significantly by treatment (Tables 4 and 5). However, planned comparisons between MAN0 and MAN1 groups revealed that the differences in density of AVP immunoreactive cell bodies approached significance $\left(F_{1}=4.34, p=0.056\right)$ with high levels of AVP in MAN0 versus MAN1 males. This difference was not observed in females; however, in females there was a trend for MAN0 females to have higher OT cell bodies in the PVN than MAN1 females $\left(F_{1}=3.41, p=0.088\right)$.

\section{PLASMA HORMONES}

There was a trend for CORT to differ in females $\left(n=36, F_{3}=2.41\right.$, $p=0.085$; Figure 8) but not in males $\left(n=40, F_{3}=0.68, p=0.569\right)$ following the EPM test, a mild stressor. MAN0 females had significantly higher CORT than MAN1 females $\left(t_{1}=2.66, p=0.012\right)$. 
Table 2 | Radiolabeled ligand binding for AVPV1a receptors (optical density) for males (means \pm SD). Groups also did not differ in V1a receptor binding.

\begin{tabular}{|c|c|c|c|c|c|c|}
\hline & MAN1 $(n=6)$ & MAN1-7 $(n=10)$ & MAN7 $(n=10)$ & MANO $(n=9)$ & Statistic $(F)$ & $p$-value \\
\hline Lateral septum & $0.263 \pm 0.04$ & $0.255 \pm 0.01$ & $0.289 \pm 0.03$ & $0.356 \pm 0.06$ & 1.56 & 0.229 \\
\hline Ventral pallidum & $0.502 \pm 0.08$ & $0.738 \pm 0.14$ & $0.727 \pm 0.14$ & $0.701 \pm 0.13$ & 0.57 & 0.641 \\
\hline Medial amygdala & $0.303 \pm 0.01$ & $0.368 \pm 0.06$ & $0.337 \pm 0.03$ & $0.427 \pm 0.08$ & 0.77 & 0.518 \\
\hline Posterior cingulate cortex & $0.251 \pm 0.03$ & $0.285 \pm 0.03$ & $0.331 \pm 0.06$ & $0.305 \pm 0.03$ & 0.48 & 0.696 \\
\hline
\end{tabular}

Table 3 | Radiolabeled ligand binding for AVPV1a receptors (optical density) for females (means \pm SD).

\begin{tabular}{|c|c|c|c|c|c|c|}
\hline & MAN1 ( $n=8)$ & MAN1-7 $(n=7)$ & MAN7 $(n=3)$ & MANO $(n=10)$ & Statistic $(F)$ & $p$-value \\
\hline Lateral septum & $0.285 \pm 0.04$ & $0.239 \pm 0.01$ & $0.299 \pm 0.01$ & $0.282 \pm 0.04$ & 0.22 & 0.880 \\
\hline Ventral pallidum & $0.717 \pm 0.12$ & $0.596 \pm 0.15$ & $0.882 \pm 0.22$ & $0.564 \pm 0.09$ & 0.91 & 0.454 \\
\hline Medial amygdala & $0.326 \pm 0.04$ & $0.419 \pm 0.06$ & $0.307 \pm 0.02$ & $0.348 \pm 0.08$ & 0.45 & 0.721 \\
\hline Posterior cingulate cortex & $0.339 \pm 0.05$ & $0.285 \pm 0.03$ & $0.301 \pm 0.04$ & $0.323 \pm 0.05$ & 0.27 & 0.847 \\
\hline
\end{tabular}

Groups also did not differ in V1a receptor binding.

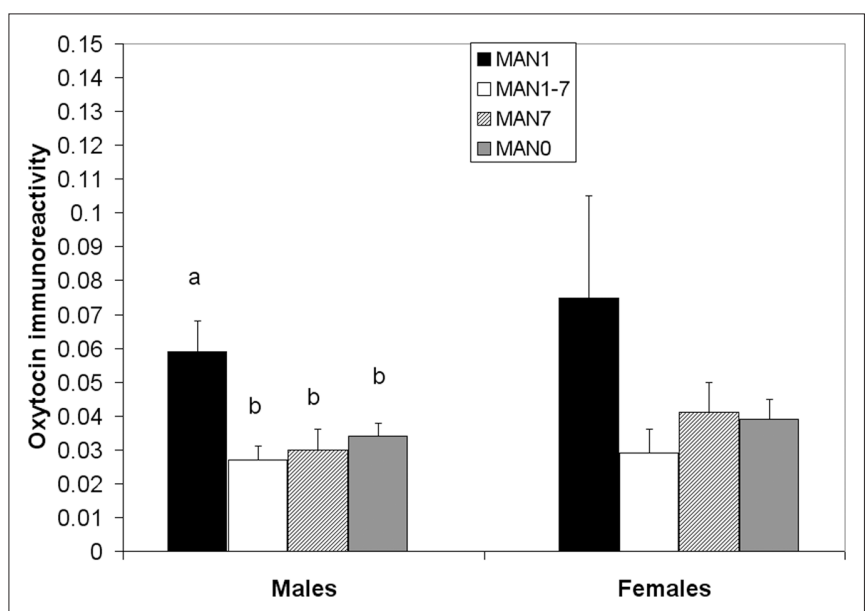

FIGURE 6 |The number of OT cell bodies in the SON differed significantly by treatment for males $\left(\boldsymbol{F}_{\mathbf{3}}=\mathbf{5 . 4 6}, \boldsymbol{p}=\mathbf{0 . 0 0 5}\right)$. Although the overall ANOVA for females was not significant $\left(F_{3}=1.9, p=0.157\right)$, there was a trend for a difference between MAN0 and MAN1 $\left(t_{1}=-1.73, p=0.096\right)$.

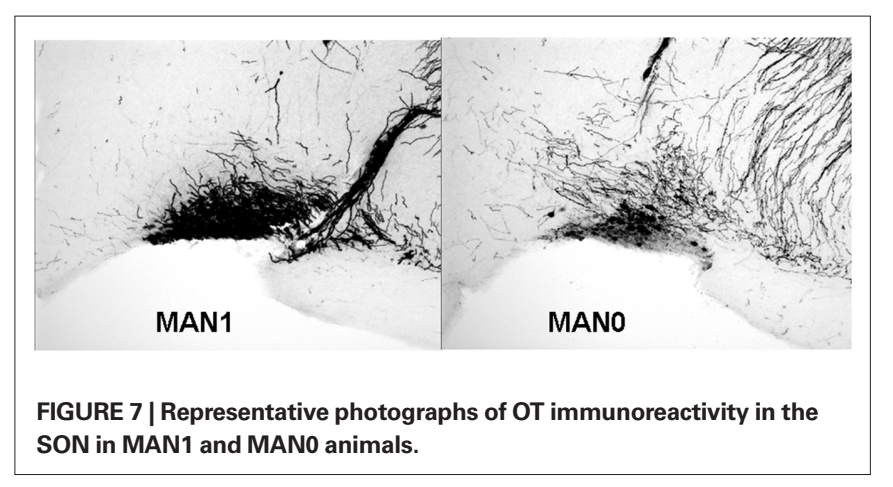

Plasma AVP did not differ significantly by treatment following the EPM test in males $\left(n=31, F_{3}=0.33, p=0.802\right.$; Figure 9) or females $\left(n=32, F_{3}=0.07, p=0.977\right)$. OT also did not differ significantly by treatment in males $\left(F_{3}=1.63, p=0.199\right.$; Figure 10$)$ or females $\left(F_{3}=1.23, p=0.316\right)$. Comparisons of MAN0 and MAN1 groups did not reveal significant effects in either sex.

\section{DISCUSSION}

The results of this study replicate earlier findings in prairie voles showing that alloparental behavior, tested in the postweaning period, can be influenced by handling during the first week of life (Bales et al., 2007a). Findings from our studies in prairie voles are consistent with literature from other mammals indicating that behavioral patterns and emotional reactions may undergo longlasting adaptations based on early experience, and possibly moderated by parental stimulation in early life. The present findings also suggest that these effects are sexually dimorphic, possibly based in part on neuroendocrine differences between the sexes in the consequences of differential early experiences.

Research in rats strongly supports the importance of early experience in determining later social and emotional responses. For example, individual differences in maternal stimulation, including licking, may influence the later expression of parental behavior by the offspring (Meaney, 2001; Pedersen and Boccia, 2002; Champagne and Meaney, 2007). In addition, in rats offspring that received moderate amounts of stimulation in early life, either by an investigator or by the mother rat, generally were more adaptable in later life, at least as measured by changes in hormones of the hypothalamic-pituitary-adrenal axis, in comparison to offspring that were deliberately left undisturbed (Levine, 1957, 2002a). Research in rats also has suggested that young animals may be particularly sensitive in the first week of life to the effects of the presence or absence of parental stimulation (Levine and Lewis, 1959a). 
Table 4 | Immunohistochemistry results for OT and AVP measures in males.

\begin{tabular}{|c|c|c|c|c|c|c|}
\hline & MAN1 $(n=6)$ & MAN1-7 ( $n=7)$ & MAN7 $(n=10)$ & MANO $(n=10)$ & Statistic $(F)$ & $p$-value \\
\hline OT cell body density - PVN & $0.170 \pm 0.04$ & $0.150 \pm 0.03$ & $0.137 \pm 0.02$ & $0.178 \pm 0.01$ & 0.96 & 0.429 \\
\hline AVP cell body density - PVN & $0.112 \pm 0.03$ & $0.119 \pm 0.02$ & $0.172 \pm 0.06$ & $0.189 \pm 0.02$ & 1.44 & 0.254 \\
\hline AVP cell body density - SON & $0.118 \pm 0.02$ & $0.159 \pm 0.02$ & $0.109 \pm 0.02$ & $0.123 \pm 0.01$ & 1.64 & 0.205 \\
\hline
\end{tabular}

Table 5 | Immunohistochemistry results for OT and AVP measures in females.

\begin{tabular}{|c|c|c|c|c|c|c|}
\hline & MAN1 $(n=5)$ & MAN1-7 $(n=7)$ & MAN7 ( $n=5)$ & MANO $(n=10)$ & Statistic $(F)$ & $p$-value \\
\hline OT cell body density - PVN & $0.124 \pm 0.02$ & $0.141 \pm 0.01$ & $0.148 \pm 0.02$ & $0.171 \pm 0.02$ & 1.21 & 0.328 \\
\hline AVP cell body density - PVN & $0.274 \pm 0.04$ & $0.161 \pm 0.05$ & $0.191 \pm 0.02$ & $0.192 \pm 0.04$ & 1.63 & 0.215 \\
\hline AVP cell body density - SON & $0.137 \pm 0.03$ & $0.087 \pm 0.02$ & $0.127 \pm 0.01$ & $0.139 \pm 0.03$ & 1.32 & 0.296 \\
\hline
\end{tabular}

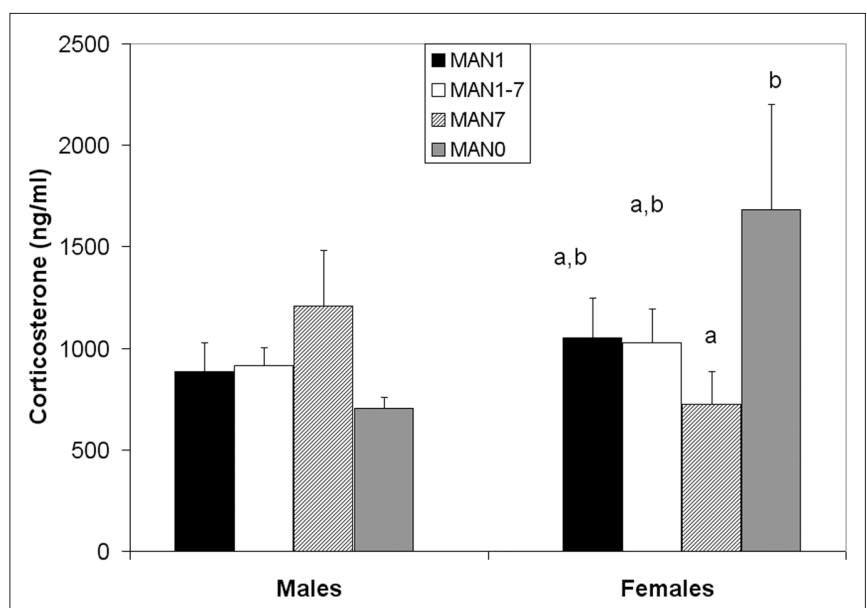

FIGURE 8 |There is a trend for stress-induced corticosterone to differ in females $\left(F_{3}=2.41, p=0.085\right)$ but not in males $\left(F_{3}=0.68, p=0.569\right)$.

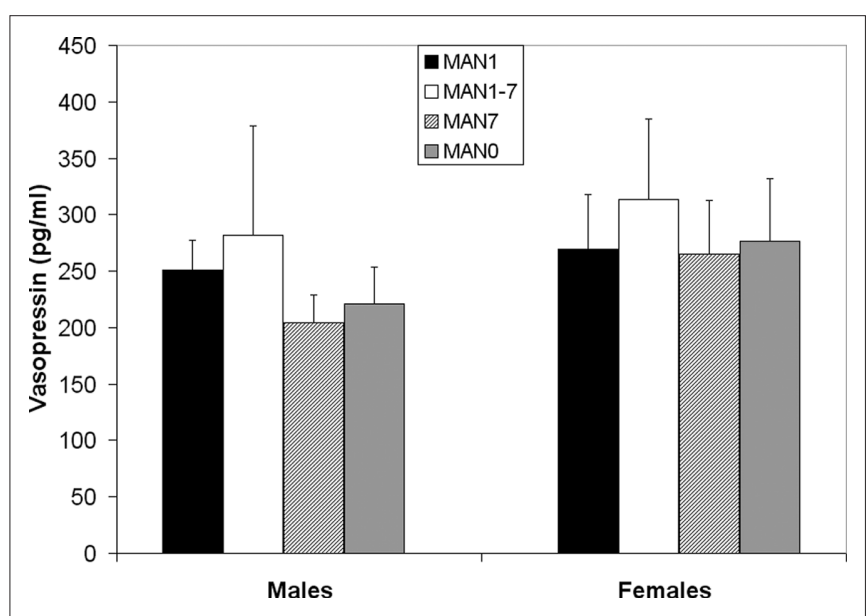

FIGURE 9 | Plasma AVP did not differ significantly by treatment following the EPM test in males $\left(F_{3}=0.33, p=0.802\right)$ or females $\left(F_{3}=0.07, p=0.977\right)$.

The present design included animals that were deliberately manipulated within the first day of post-natal life (MAN1) and those that were left undisturbed for at least one week (MAN0)

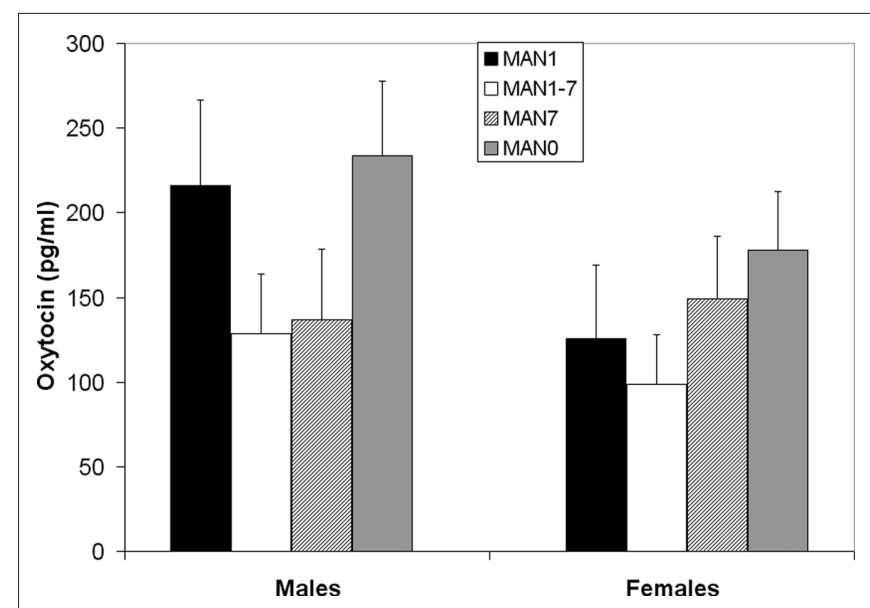

FIGURE 10 | Plasma OT did not differ significantly by treatment in males $\left(F_{3}=1.63, p=0.199\right)$ or females $\left(F_{3}=1.23, p=0.316\right)$.

with minimal disturbance through out the rest of the pre-weaning period. As in previous studies the male offspring of the manipulated group (MAN1) showed higher levels of later alloparenting compared to the MAN0 males (Bales et al., 2007a). However, when the first experience of manipulation was postponed until postnatal day 7 (MAN7), the male offspring showed an alloparenting pattern more similar to that seen in animals that were not handled (MAN0). We also examined the hypothesis that more frequent manipulation, daily during the first week of life (MAN1-7), would further increase alloparenting. However, no difference in alloparenting was observed between MAN1 and MAN1-7 males; a high proportion of both MAN1 (67\%) and MAN1-7 (75\%) showed alloparental behavior. In contrast, the proportion of alloparental males was much lower in the MAN0 (33\%) and MAN7 (20\%) groups. Female alloparenting did not vary significantly with early manipulation, as was also found in the previous study (Bales et al., 2007a); 54\% of MAN0 females and 38\% of MAN7 females showed alloparental behavior, with $40 \%$ of MAN 1 and $60 \%$ of MAN1-7 females displaying alloparenting.

In the present study, because the full family including both parents and their infants were manipulated, it was not possible to determine whether the observed changes were due to 
direct stimulation of the young or mediated through differential parenting. However, immediately following handling we observed that both parents, and especially mothers, directed increased levels of stimulation toward their pups, including licking and grooming (Tyler et al., 2005). In contrast, undisturbed families were less interactive with pups, especially on the first day of life. More recently, we have also examined the consequences in prairie voles of repeated handling, three times at 3-4 h intervals on post-natal day. Immediately following the third episode of handling, parents showed reductions in interactions with their infants. As in the MAN0 treatment, the male offspring from this repeated handling group showed low levels of alloparenting in later life (Boone et al., 2009). Taken together with the results of the present study, these findings suggest that in male prairie voles reduced parental stimulation, especially in the immediate post-natal period, may contribute to the deficits in later alloparenting observed after either reduced or repeated handling.

Both MAN0 and MAN7 males (which displayed low alloparenting) also produced less OT in the SON than MAN1 males. In contrast, MAN1-7 males displayed both high alloparenting and low OT. One hypothesis for future studies is that MAN1-7 males might compensate for low OT production with higher AVP production. While MAN1-7 had low OT in the SON, their AVP in the SON was relatively high (Table 4). We did not present post hoc comparisons in the table due to the non-significant findings in the main ANOVA, but if performed, MAN1-7 males did have significantly higher AVP cell bodies in the SON than MAN7 males $(p=0.05)$ and displayed a non-significant trend for higher values than MAN0 males $(p=0.11)$. Previous research has shown that male prairie voles can facilitate alloparenting through either the OT or AVP system (Bales et al., 2004b).

As in our previous study, we found sex differences in the effects of handling treatments. While in females we found no difference in alloparenting, we did find differences in behaviors that may reflect anxiety. Our previous study comparing MAN1 and MAN0 (Bales et al., 2007a) showed higher levels of anxiety-like behaviors in MAN0 animals, as measured in the EPM, which we did not detect here. In fact, we found the opposite: MAN0 females tended to spend less time in the closed arms of the EPM than MAN1 females. This could be due to the age of testing, as the previous study tested animals at 60 days of age while in the present study animals were tested at 22 days (directly after weaning). In animal models, changes of anxiety with age are a common finding although the direction is not always consistent (Lynn and Brown, 2010). In the current study, changes in gonadal hormones are an unlikely mechanism for age-related changes in anxiety because prairie voles are induced ovulators (Carter et al., 1980). However, changes in peptide systems could be a possibility; we are not aware of any studies directly comparing adolescent and adult production of OT or AVP in prairie voles. A second possibility is that time since receiving other tests could have affected the outcome of the EPM. In Bales et al. (2007a, 2007b) the adult voles had not received another behavioral test for approximately 38 days; while in the present study, the juvenile voles had received the alloparenting test the day before they received the EPM. It is therefore possible that in this study, the alloparenting test was residually affecting the EPM in some fashion.
In females, we did observe significant treatment differences in autogrooming in the EPM. Interestingly, the two groups in the present study which received reduced manipulation in the first week of life (MAN0 and MAN7), displayed very different autogrooming behavior in the EPM; this suggests that there may not be a critical period for handling effects on this particular behavior, or at least that it is longer than one week. MAN0 females autogroomed the least of all groups (Figure 2). MAN0 females may be displaying a more passive coping style, with higher levels of CORT released during stress and lower autogrooming in response to stress; MAN7 females, on the other hand, display an active response (autogrooming) resulting in lower CORT levels. The same patterns were not seen in males. These findings are consistent with the hypothesis that coping strategies in the face of challenge differ between males and females (Koolhaas et al., 2001, 2007), especially when these challenges occur in early life (Carter et al., 2009). However, the experiential factors that differentiate the MAN0 and MAN7 paradigms remain to be described. There might be age-related differences in the dependence of the offspring on parental stimulation. Alternatively, parents of pups of different ages may differ in their reactions to experiences (or the absence of experiences).

The MAN1-7 group in particular presents several challenges of interpretation. Above, we discussed the possible role of increased AVP in the SON in normalizing alloparenting behavior in MAN1-7 males. MAN1-7 females were similar to MAN1 females on almost every measure except for autogrooming in the EPM, where they showed increased autogrooming compared to all other groups, perhaps suggestive of increased anxiety. In females, we did not do post hoc comparisons between groups due to non-significance of the overall ANOVA for OT in the SON. However, a direct comparison between MAN1 and MAN1-7 females does suggest lower OT-IR in the SON in MAN1-7 females $(p=0.025)$.

One purpose of this study was to examine the hypothesis that changes in central neuropeptide systems might mediate the longterm consequences of early experience. In the present study, the OT system, and especially the OTR, responded to variations in early experiences, whereas changes were less obvious in the V1aR system. In contrast, a series of studies of the effects of exposure to exogenous OT on post-natal day 1 (Bales and Carter, 2003a, 2003b; Bales et al., 2004a, 2004c), revealed changes in the V1aR, but with no detectable differences in OTRs or dopamine D2 receptors (Bales et al., 2007b). The source of these differences has not been identified. However, exogenous OT, possibly given at a pharmacological dose, might have produced secondary binding to V1aRs (Gimpl and Fahrenholz, 2001). In addition, the age of the animals at the time of sacrifice differed between the two studies.

The effects most apparent in females from the MAN0 group were increased OTR binding in the NAcc, the BNST, and LS. The higher availability of OTR may be related to the lower anxiety displayed by MAN0 females at this age. OT is generally anxiolytic (Neumann, 2002; Labuschagne et al., 2010). It is possible that the elevated OTRs in these brain regions are a response to lower OT peptide availability, either during development (due to decreased stimulation by parents) or during adulthood (Figure 5). We would hypothesize that lower OT during development is more likely, given that MAN0 females actually had higher OT production in the PVN in this study than MAN1 females. Although the SON is unlikely 
to be the major source of OT peptide to these areas, recent studies have shown that the SON in prairie voles does have oxytocinergic projections to the NAcc (Ross et al., 2009).

Variations in early handling were associated with later changes in neuropeptide production and binding, although these relationships differed for males and females. MAN0 males displayed elevated OTR in the BNST, lower OT production in the SON, and elevated AVP production in the PVN when compared to MAN1 males. Previous literature has suggested that male prairie voles can facilitate alloparenting behavior through either the OT or the AVP system (Bales et al., 2004b). It is possible that extensive dysregulation, rather than changes in one particular neuropeptide or neuropeptide receptor, may have affected alloparenting behavior in this paradigm.

The results of this study are also consistent with preliminary data on methylation in a $\mathrm{CpG}$ island in the promoter region of the OTR gene. In these studies animals from a MAN1 group demonstrated higher levels of methylation in tissue from the NAcc compared to MAN0 animals in which methylation was low (Connelly and Carter, unpublished data). Low levels of methylation would be expected to permit increased expression of the OTR, which was the outcome seen in females in the MAN0 group in the present study (Figure 3). Other preliminary studies from our group suggest that OT may increase methylation of the OTR gene (Connelly and Carter, unpublished data). At the time of sampling in the present study, PND 22, OT synthesis in the SON (indexed by immunohistochemical staining) was higher in MAN1 animals than in any other group. This effect was seen in both sexes, although was only significant in males. It is still unknown whether OT levels at the time of the handling treatment were enhanced in MAN1 animals, but that would be consistent with other findings.

Oxytocin production in the SON also may occur in response to chronic stress (Neumann, 2002; Grippo et al., 2007); stress in turn might increase subsequent synthesis or release of AVP (Neumann et al., 2006). It is possible that the higher levels of SON OT available to MAN1 animals may impact on their stress systems (perhaps by other measures than those shown here), and in prairie voles stress is well-known to affect social behavior (DeVries et al., 1995, 1996; Bales et al., 2006). In rats, maternal separation resulted in an increase in AVP immunoreactivity in SON (Veenema et al., 2006). In the present study, there are preliminary indications that AVP, especially in males, might be upregulated in the MAN0 group, which might also be receiving less parental stimulation.

\section{REFERENCES}

Advani, T., Hensler, J. G., and Koek, W. (2007). Effects of early rearing conditions on alcohol drinking and 5- $\mathrm{HT}_{1 \mathrm{a}}$ receptor function in C57BL/6J mice. Int. J. Neuropsychopharmacol. 10, 595-607.

Aguilar, R. (2010). Infantile experience and play motivation. Soc. Neurosci. 5, 422-440.

Aisa, B., Tordera, R., Lasheras, B., Del Rio, J., and Ramirez, M. J. (2008). Effects of maternal separation on hypothalamic-pituitary-adrenal responses, cognition, and vulnerability to stress

\section{CONCLUSIONS}

Differential early handling experiences in prairie voles were associated with long-term, sexually dimorphic changes in social and anxiety-related behaviors, as well as neuroendocrine parameters. As a whole, these measures indicate that subtle variations in early experience, perhaps mediated by changes in the behavior of the parents following disruptions of the family (Tyler et al., 2005) can have long-term effects on social behaviors in prairie voles. The disruptive effects on alloparental behavior of reduced manipulation during the first few days of life (MAN0), when compared to those of animals that were handled (MAN1), were similar to those observed in previous studies (Bales et al., 2007a). In males, daily manipulations of the family (MAN1-7) also produced effects on alloparenting that were similar to those seen in MAN1 and when manipulations were delayed until post-natal day 7 (MAN7), the consequences for subsequent alloparental behavior were similar to MAN0. However, the neuroendocrine effects of MAN1-7 versus MAN1 and the effects of MAN7 versus MAN0 were not always similar. These results suggest that different amounts of handling and manipulations during different time periods have behavioral effects that are not identical to those for neuroendocrine systems.

The present findings yielded complex group differences in behavior and neuroendocrine measures. These findings do not allow strong conclusions regarding the causal roles of OT or AVP in alloparental- or anxiety-related behaviors. However, we cannot exclude the possibly that the behavioral results obtained here reflect interactions between the OT and AVP systems, and that both show adaptive changes adjusting the expression of social behavior and responsivity to novel environments.

While we did not measure changes in OT at the time of the early experience we did find long-term treatment effects on the OT system, with increases in the OTR in females. In general, changes in AVP were less obvious.

\section{ACKNOWLEDGMENTS}

We are grateful for research support from NIMH (RO1 073022 to C. Sue Carter and Karen L. Bales), the National Alliance for Autism Research (to C. Sue Carter), and NSF (0437523 to Karen L. Bales). We thank the following for help in performing these studies: Antoniah Lewis-Reese, Lisa Sanzenbacher, Amber Tyler, Julie Van Westerhuyzen, Alex Kowalczyk, Thinh Hoang, Julie Hazelton, Nathaniel Grotte, and Soraya Foutouhi. We also thank Drs. Terry Hewett and Jim Artwohl for veterinary care.

of manipulations of oxytocin on alloparenting and anxiety in prairie voles. Dev. Psychobiol. 44, 123-131.

Bales, K. L., and Carter, C. S. (2003a). Developmental exposure to oxytocin facilitates partner preferences in male prairie voles (Microtus ochrogaster). Behav. Neurosci. 117 854-859.

Bales, K. L., and Carter, C. S. (2003b). Sex differences and developmental effects of oxytocin on aggression and social behavior in prairie voles (Microtus ochrogaster). Horm. Behav. 44, 178-184.
Bales, K. L., Kramer, K. M., Lewis-Reese, A. D., and Carter, C. S. (2006). Effects of stress on parental care are sexually dimorphic in prairie voles. Physiol. Behav. 87, 424-429.

Bales, K. L., Lewis-Reese, A. D., Pfeifer, L. A., Kramer, K. M., and Carter, C. S. (2007a). Early experience affects the traits of monogamy in a sexually dimorphic manner. Dev. Psychobiol. 49, 335-342.

Bales, K. L., Plotsky, P. M., Young, L. J., Lim, M. M., Grotte, N. D., Ferrer, E., and Carter, C. S. (2007b). Neonatal oxytocin manipulations have long-lasting, 
sexually dimorphic effects on vasopressin receptors. Neuroscience 144, 38-45.

Berardi, N., Braschi, C., Capsoni, S., Cattaneo, A., and Maffei, L. (2007). Environmental enrichment delays the onset of memory deficits and reduces neuropathological hallmarks in a mouse model of Alzheimer-like neurodegeneration. J. Alz. Dis. 11, 359-370.

Bester-Meredith, J. K., and Marler, C. A. (2003). Vasopressin and the transmission of paternal behavior across generations in mated, cross-fostered Peromyscus mice. Behav. Neurosci. 117, 455-463.

Boccia, M. L., and Pedersen, C. A. (2001). Brief vs. long maternal separations in infancy: contrasting relationships with adult maternal behavior and lactation levels of aggression and anxiety. Psychoneuroendocrinology 26, 657-672.

Boone, E. M., Sanzenbacher, L. L., Stanfill, S. D., Bales, K. L., and Carter, C. S. (2009). Oxytocin injections in early life reversed negative behavioral effects of repeated handling. Soc. Neurosci. Abstr. 468.12.

Carter, C. S., Boone, E. M., PournajafiNazarloo, H., and Bales, K. L. (2009). Consequences of early experience and exposure to oxytocin and vasopressin are sexually dimorphic. Dev. Neurosci. 31, 332-341.

Carter, C. S., DeVries, A.C ., and Getz, L. L. (1995). Physiological substrates of mammalian monogamy: the prairie vole model. Neurosci. Biobehav. Rev. 19, 303-314.

Carter, C. S., Getz, L. L., Gavish, L., McDermott, J. L., and Arnold, P. (1980). Male-related pheromones and the activation of female reproduction in the prairie vole (Microtus ochrogaster). Biol. Repro. 23, 1038-1045.

Champagne, F., Diorio, J., Sharma, S., and Meaney, M. J. (2001). Naturally occurring variations in maternal behavior in the rat are associated with differences in estrogen-inducible central oxytocin receptors. Proc. Natl. Acad. Sci. U.S.A. 98, 12736-12741.

Champagne, F. A., and Meaney, M. J. (2007). Transgenerational effects of social environment on variations in maternal care and behavioral response to novelty. Behav. Neurosci. 121, 1353-1363.

Cho, M. M., DeVries, A. C., Williams, J. R. and Carter, C.S. (1999). The effects of oxytocin and vasopressin on partner preferences in male and female prairie voles (Microtus ochrogaster). Behav. Neurosci. 113, 1071-1079.

Denenberg, V. H., Ottinger, D. R., and Stephans, M. W. (1962). Effects of maternal factors upon growth and behavior of the rat. Child Dev. 33 , 65-71.

Denenberg, V. H., and Whimbey, A. E. (1963). Infantile stimulation and animal husbandry: a methodological study. J. Comp. Physiol. Psych. 56, 877-878.

Desbonnet, L., Garrett, L., Daly, E., McDermott, K. W., and Dinan, T. G. (2008). Sexually dimorphic effects of maternal separation stress on corticotrophin-releasing factor and vasopressin systems in the adult rat brain Int. J. Dev. Neurosci. 26, 259-268.

DeVries, A.C., DeVries, M. B., Taymans, S., and Carter, C. S. (1995). The modulation of pair bonding by corticosterone in female prairie voles (Microtus ochrogaster). Proc. Natl. Acad. Sci. U.S.A.92, 7744-7748.

DeVries, A. C., DeVries, M. B., Taymans, S. E., and Carter, C. S. (1996). The effects of stress on social preferences are sexually dimorphic in prairie voles. Proc. Natl. Acad. Sci. U.S.A. 93, 11980-11984.

Dharmadhikari, A., Lee, Y. S., Roberts, R. L., and Carter, C. S. (1997). Exploratory behavior correlates with social organization and is responsive to peptide injections in prairie voles. Ann. N. Y. Acad. Sci. 807, 610-612.

Eklund, M. B., and Arborelius, L. (2006) Twice daily long maternal separations in Wistar rats decreases anxiety-like behaviour in feamles but does not affect males. Behav. Brain Res. 172 278-285.

Enthoven, L., de Kloet, E. R., and Oitzl, M. S. (2008). Differential development of stress system (re)activity at weaning dependent on disruption of maternal care. Brain Res. 1217, 62-69.

Francis, D. D., Diorio, J., Plotsky, P.M., and Meaney, M. J. (2002a). Environmental enrichment reverses the effects of maternal separation on stress reactivity. J. Neurosci. 22, 7840-7843.

Francis, D. D., Young, L. J., Meaney, M. J., and Insel, T. R. (2002b). Naturally occurring differences in maternal care are associated with the expression of oxytocin and vasopressin (V1a) receptors: gender differences. J. Neuroendocrin. 14, 349-353.

Francis, D. D., and Kuhar, M. J. (2008). Frequency of maternal licking and grooming correlates negatively with vulnerability to cocaine and alcohol use in rats. Pharmacol. Biochem. Behav. 90, 497-500.

Francis, D. D., Young, L. J., Meaney, M. J., and Insel, T. R. (2000). Variations in maternal behavior are associated with differences in oxytocin receptors levels in the rat. J. Neuroendocrin. 12, 1145-1148.

Getz, L. L., Carter, C. S., and Gavish, L. (1981). The mating system of the prairie vole Microtus ochrogaster: field and laboratory evidence for pair-bonding. Behav. Ecol. Sociobiol. 8, 189-194.

Gilmer,W.S., and McKinney,W.T. (2003). Early experience and depressive disorders: human and non-human primate studies. J. Aff. Dis. 75, 97-113.

Gimpl, G., and Fahrenholz, F. (2001). The oxytocin receptor system: structure, function, and regulation. Physiol. Rev. 81, 629-683.

Grippo, A. J., Gerena, D., Huang, J. Kumar, N., Shah, M., Ughreja, R., and Carter, C. S. (2007). Social isolation induces behavioral and neuroendocrine disturbances relevant to depression in female and male prairie voles. Psychoneuroendocrinology 32 966-980.

Harlow, H. F.(1961). “The development of affectional patterns in infant monkeys," in Determinants of Infan Behavior, ed. B. M. Foss (New York: Wiley), 75-97.

Harlow, H. F.(1964). “Early social deprivation and later behavior in the monkey," in Unfinished Tasks in the Behaviora Sciences, eds A. Abrams, H. H. Garner, and J. E. P. Tomal (Baltimore, MD: Williams \& Wilkins), 154-173.

Harlow, H. F., and Suomi, S. J. (1971) Social recovery of isolation-reared monkeys. Proc. Natl. Acad. Sci. U.S.A 68, 1534-1538.

Heim, C., Owens, M. J., Plotsky, P. M., and Nemeroff, C. B. (1997). The role of early adverse life events in the etiology of depression and posttraumatic stress disorder - focus on corticotropinreleasing factor. Psychobiol. Posttraum. Stress Disord. 821, 194-207.

Henry, J. P., and Wang, S. (1998). Effects of early stress on adult affiliative behavior. Psychoneuroendocrinology 23, 863-875.

Herring, A., Yasin, H., Ambree, O., Sachser, N., Paulus, W., and Keyvani, K. (2008) Environmental enrichment counteracts Alzheimer's neurovascular dysfunction in TgCRND8 mice. Brain Path. 18, 32-39.

Hofer, M. A.(1978). "Hidden regulatory processes in early social relationships," in Perspectives in Ethology, Vol. 3, eds P. P. G. Bateson and P. H. Klopfer (New York: Plenum Press), 135-166.

Hofer, M. A. (2006). Psychobiological roots of early attachment. Curr. Dir. Psychol. Sci. 15, 84-88.

Holmes, A., le Guisquet, A. M., Vogel, E., Millstein, R. A., Leman, S., and Belzung, C. (2005). Early life genetic, epigenetic, and environmental factors shaping emotionality in rodents. Neurosci.Biobehav. Rev. 29, 1335-1346.

Insel, T. R., Preston, S., and Winslow, J. T (1995). Mating in the monogamous male: Behavioral consequences. Physiol. Behav. 57, 615-627.
Koolhaas, J. M., de Boer, S. F, Buwalda, B. and van Reenen, K. (2007). Individual variation in coping with stress: a multidimensional approach of ultimate and proximate mechanisms. Brain Behav. Evol. 70, 218-226.

Koolhaas, J. M., de Boer, S. F., Buwalda, B., van der Vegt, B. N., Carere, C., Groothuis, A. G. G.(2001). "How and why coping systems vary among individuals," in Coping With Challenge: Welfare in Animals Including Humans, ed. D. M. Broom (Dahlem Workshop Report \#87), 197-209.

Kramer, K. M., Cushing, B. S., Carter, C.S., Wu, J., and Ottinger, M.A. (2004). Sex and species differences in plasma oxytocin using an enzyme immunoassay. Can. J. Zool. 82, 1194-1200.

Labuschagne, I., Phan, K. L., Wood, A., Angstadt, M., Chua, P., Heinrichs, M. Stout, J. C., and Nathan, P. J. (2010). Oxytocin attenuates amygdala reactivity to fear in generalized social anxiety disorder. Neuropsychopharmacology $35,2403-2413$.

Levine, S. (1957). Infantile experience and resistance to physiological stress. Science 126, 405.

Levine, S.(2002a). "Enduring effects of early experience on adult behavior," in Hormones, Brain and Behavior, eds D. W. Pfaff, A. P. Arnold, A. M. Etgen, S. E. Fahrbach, and R. T. Rubin (New York: Academic Press), 535-542.

Levine, S. (2002b). Regulation of the hypothalamic-pituitary-adrenal axis in the neonatal rat: the role of maternal behavior. Neurotox. Res. 4, 557-564.

Levine, S. (2005). Developmental determinants of sensitivity and resistance to stress. Psychoneuroendocrinology 30, 939-946.

Levine, S., and Lewis, G. W. (1959a). Critical period for effects of infantile experience on maturation of stress. Science 129, 42-43.

Levine, S., and Lewis, G. W. (1959b). The relative importance of experimenter contact in an effect produced by extra-stimulation in infancy. J. Comp. Physiol. Psychol. 52, 368-369.

Lim, M. M., Hammock, E. A. D., and Young, L. J. (2004). The role of vasopressin in the genetic and neural regulation of monogamy. J. Neuroendocrin. 16, 325-332.

Littell, R., Milliken, G. A., Stroup, W W., and Wolfinger, R. D. (1996). SAS System for Mixed Models. Cary, NC: SAS Institute Inc.

Lynn, D. A., and Brown, G. R. (2010). The ontogeny of anxiety-like behavior in rats from adolescence to adulthood. Dev. Psychobiol. 52, 731-739.

Macri, S., Chiarotti, F., and Wurbel, H (2008). Maternal separation and maternal care act independently on the development of HPA responses 
in male rats. Beh. Brain Res. 191, 227-234.

Meaney, M. J. (2001). Maternal care, gene expression, and the transmission of individual differences in stress reactivity across generations. Ann. Rev. Neurosci. 24, 1161-1192.

Neumann, I. D. (2002). Involvement of the brain oxytocin system in stress coping: interactions with the hypothalamopituitary-adrenal axis. Prog. Brain Res. 139, 147-162.

Neumann, I. D., Torner, L., Toschi, N., and Veenema, A. H. (2006). Oxytocin actions within the supraoptic and paraventricular nuclei: differential effects on intranuclear and peripheral vasopressin release. Am. J. Physiol. Integr. Comp. Physiol. 291, R29-R36.

Nithianantharajah, J., and Hannan, A. J. (2006). Enriched environments, experience-dependent plasticity and disorders of the nervous system. Nat. Rev. Neurosci. 7, 697-709.

Paxinos, G., and Watson, C. (2005). Rat Brain in Stereotaxic Coordinates, 5th Edn. New York: Elsevier.

Pedersen, C.A., Ascher, J.A., Monroe, Y.L., and Prange, A. J. Jr. (1982). Oxytocin induces maternal behavior in virgin female rats. Science 216, 648-650.

Pedersen, C. A., and Boccia, M. L. (2002). Oxytocin links mothering received, mothering bestowed, and adult stress responses. Stress 5, 267.

Plotsky, P. M. (1997). Long-term consequences of adverse early experience: a rodent model. Biol. Psychiat. 41, 262.

Plotsky, P. M. (2002). Altering the developmental trajectory of the brain: Short and long term consequences of early experience in animal models. Biol. Psychiat. 51, 100S.

Plotsky,P.M.,Owens,M.J., and Nemeroff,C. B. (1998). Psychoneuroendocrinology of depression - Hypothalamicpituitary-adrenal axis. Psychiatr. Clin. North Am. 21, 293-307.

Ramos, A., and Mormede, P. (1998). Stress and emotionality: a multidimentional and genetic approach. Neurosci. Biobehav. Rev. 22, 33-57.

Renard, G.M., Rivarola, M.A., and Suarez, M. M. (2007). Sexual dimorphism in rats: effects of early maternal separation and variable chronic stress on pituitary-adrenal axis and behavior. Int. J. Dev. Neurosci. 25, 373-379.

Roberts, R. L., Williams, J. R., Wang, A. K., and Carter, C. S. (1998). Cooperative breeding and monogamy in prairie voles: influence of the sire and geographical variation. Anim. Behav. 55, 1131-1140.

Ross, H. E., Cole, C. D., Smith, Y., Neumann, I. D., Landgraf, R., Murphy, A. Z., and Young, L. J. (2009). Characterization of the oxytocin system regulating affiliative behavior in female prairie voles. Neuroscience 162, 892-903.

Ruscio, M. G., Sweeny, T., Hazelton, J. L., Suppatkul, P., and Carter, C. S. (2007). Social environment regulates corticotropin releasing factor, corticosterone and vasopressin in juvenile prairie voles. Horm. Behav. 51, 54-61.

Sanchez, M. M., Ladd, C. O., and Plotsky, P. M. (2001). Early adverse experience as a developmental risk factor for later psychopathology: Evidence from rodent and primate models. Dev. Psychopathol. 13, 419-449.

Slotten, H. A., Kalinichev, M., Hagan, J. J., Marsden, C. A., and Fone, K. C. F. (2006). Long-lasting changes in behavioural and neuroendocrine indices in the rat following neonatal maternal separation: gender-dependent effects. Brain Res. 1097, 125-132.

Smotherman, W. P., and Bell, R. W.(1980). "Maternal mediation of early experience," in Maternal Influence and Early Behavior, eds W. P. Smotherman, and R. W. Bell (New York: Spectrum Publishing).

Stowe, J. R., Liu, Y., Curtis, J. T., Freeman, M. E., and Wang, Z. X. (2005). Species differences in anxiety-related responses in male prairie and meadow voles: The effects of social isolation. Physiol. Behav. 86, 369-378.

Tang, A. C. (2001). Neonatal exposure to novel environment enhances hippocampal-dependent memory function during infancy and adulthood. Learn. Mem. 8, 257-264.

Tang, A. C., Akers, K. G., Reeb, B. C., Romeo, R. D., and McEwen, B. S. (2006). Programming social, cognitive, and neuroendocrine development by early exposure to novelty. Proc. Natl. Acad. Sci. U.S.A. 103, 15716-15721.

Taymans, S. E., DeVries, A. C., DeVries, M. B., Nelson, R. J., Friedman, T. C., Detera-Wadleigh, S., Carter, C. S., and Chrousos, G. P. (1997). The hypothalamic-pituitary-adrenal axis of prairie voles (Microtus ochrogaster): evidence for target tissue glucocorticoid resistance. Gen. Comp. Endocrinol. 106, 48-61.

Todeschin, A. S., Winkelmann-Duarte, E. C., Jacob, M. H. V., Aranda, B. C. C., Jacobs, S., Fernandes, M. C., Ribeiro, M. F.M., Sanvitto, G. L., and Lucion, A. B. (2009). Effects of neonatal handling on social memory, social interaction, and number of oxytocin and vasopressin neurons in rats. Horm. Behav. 56, 93-100.

Tyler, A. N., Michel, G. F., Bales, K. L., and Carter, C. S. (2005). Do brief early disturbances of parents affect parental care in the bi-parental prairie vole (Microtus ochrogaster)? Dev. Psychobiol. 47, 451.

Veenema, A. H., Blume, A., Niederle, D., Buwalda, B., and Neumann, I. D. (2006). Effects of early life stress on adult male aggression and hypothalamic vasopressin and serotonin. Eur. J. Neurosci. 24, 1711-1720.

Wang, Z. X., Ferris, C. F., and Devries, G. J. (1994). Role of septal vasopressin innervation in paternal behavior in prairie voles (Microtus ochrogaster). Proc. Natl. Acad. Sci. U.S.A. 91, 400-404.
Wang, Z. X., Zhou, L., Hulihan, T. J., and Insel, T. R. (1996). Immunoreactivity of central vasopressin and oxytocin pathways in microtine rodents: a quantitative comparative study. $J$. Comp. Neurol. 366, 726-737.

Williams, J. R., Insel, T. R., Harbaugh, C. R., and Carter, C. S. (1994). Oxytocin centrally administered facilitates formation of a partner preference in female prairie voles (Microtus ochrogaster). J. Neuroendocrin. 6, 247-250.

Winslow, J. T., Hastings, N., Carter, C. S., Harbaugh, C. R., and Insel, T. R. (1993). A role for central vasopressin in pair bonding in monogamous prairie voles. Nature 365, 545-548.

Zanettini, C., Carola, V., Lo Iacona, L., Moles, A., Gross, C., and d'Amato, F. R. (2010). Postnatal handling reverses social anxiety in serotonin receptor $1 \mathrm{~A}$ knockout mice. Genes Brain Behav. 9, 26-32.

Conflict of Interest Statement: The authors declare that the research was conducted in the absence of any commercial or financial relationships that could be construed as a potential conflict of interest.

Received: 19 February 2011; accepted: 24 April 2011; published online: 09May 2011. Citation: Bales KL, Boone E, Epperson P, Hoffman G and Carter CS (2011) Are behavioral effects of early experience mediated by oxytocin?. Front. Psychiatry 2:24. doi: 10.3389/fpsyt.2011.00024

This article was submitted to Frontiers in Child and Neurodevelopmental Psychiatry, a specialty of Frontiers in Psychiatry. Copyright $\odot 2011$ Bales, Boone, Epperson, Hoffman and Carter. This is an openaccess article subject to a non-exclusive license between the authors and Frontiers Media SA, which permits use, distribution and reproduction in other forums, provided the original authors and source are credited and other Frontiers conditions are complied with. 